\title{
Correction to: PRSS21/testisin inhibits ovarian tumor metastasis and antagonizes proangiogenic angiopoietins ANG2 and ANGPTL4
}

\author{
Gregory D. Conway ${ }^{1} \cdot$ Marguerite S. Buzza $^{1} \cdot$ Erik W. Martin $^{1} \cdot$ Nadire Duru $^{1} \cdot$ Tierra A. Johnson ${ }^{1}$. \\ Raymond J. Peroutka ${ }^{1}$ - Nisha R. Pawar ${ }^{1}$. Toni M. Antalis ${ }^{1}$
}

Published online: 20 July 2019

(C) Springer-Verlag GmbH Germany, part of Springer Nature 2019

Correction to: Journal of Molecular Medicine (2019) 97:691-709

https://doi.org/10.1007/s00109-019-01763-3

The affiliation of Erik W. Martin is corrected in this paper.

Pulisher's note Springer Nature remains neutral with regard to jurisdictional claims in published maps and institutional affiliations

The online version of the original article can be found at https://oi.org/ 10.1007/s00109-019-01763-3

Toni M. Antalis

tantalis@som.umaryland.edu

1 Center for Vascular and Inflammatory Diseases, Department of Physiology, and the University of Maryland Marlene and Stewart Greenebaum Comprehensive Cancer Center, University of Maryland School of Medicine, 800 West Baltimore Street Rm 220,

Baltimore, MD 21201, USA 